\title{
Development and validation of a stochastic disaster impact model
}

\author{
R. Dudensing ${ }^{1}$, J. Richardson ${ }^{2} \&$ R. Lu $^{3}$ \\ ${ }^{1}$ Texas AgriLife Extension Service, Texas A\&M University, USA \\ ${ }^{2}$ Agriculture Food Policy Center, Texas A\&M University, USA \\ ${ }^{3}$ Department of Agricultural Economics, Texas A\&M University, USA
}

\begin{abstract}
Natural disasters result in economic losses as capital and industry are destroyed, as transportation and communication lines are severed, and as customers temporarily flee a region. In many cases, production and sales levels remain depressed as the region rebuilds. Furthermore, these direct losses account for only a portion of the total economic loss experienced.

This paper presents a disaster impact model (DIM) to quantify the economic impact of natural disasters on regional output, GDP contribution, labor income, tax income, and employment, as well as the time to recovery. The model is developed to measure the impact of Hurricane Ike on eight Texas Gulf Coast counties and is then extended to a wildfire in central Texas. Actual county sales data are modeled for a period of years before the event, accounting for trends over time and between fiscal quarters, and are used to predict quarterly and annual sales by industry and agricultural commodity in post-event quarters. IMPLAN input-output multipliers are applied to the predicted sales, and stochastic estimates of total impacts are generated using Simetar. Actual postevent impacts are then compared to predicted impacts to estimate the quarterly and annual total economic losses attributable to each industry. Losses are reported at the county and state levels for individual industries as well as across the regional economy. Results show that Hurricane Ike (and a global recession) impacted the coastal economy negatively for at least three years after the event, and industries and locations exhibited different initial responses and recovery paths. Wildfire losses were more sector-specific and shorter in duration.
\end{abstract}

Keywords: disaster impact model, disaster economic impact, resilience, stochastic model. 


\section{Introduction}

Natural disasters cause widespread damage to structures, machinery, and inventories within a region. The need to replace capital and inventories is complicated by decimated transportation and communication networks and by residents (labor force and consumers) and visitors (consumers) fleeing the area. Thus, it can take months or years before a region's economy is able to rebuild.

Local and state officials, business leaders, and residents want to restore the regional economy quickly. Understanding the recovery patterns of various businesses can help leaders to identify opportunities to improve resilience. This paper discusses the development of a disaster impact model (DIM), using data from an eight-county study area in coastal Texas prior to and immediately following Hurricane Ike. Ideally, a DIM will be generalizable across various types of disasters. Therefore, the model is adapted for a wildfire in central Texas.

The economy of the Texas Gulf coast in the U.S. was severely impacted by Hurricane Ike in September 2008. The storm began as a Cape Verde-type storm off the coast of Africa in late August. The storm surge topped the Galveston, Texas, seawall on September 12, and the storm made final landfall in Galveston County on September 13 as a category 2 hurricane with sustained winds of 175 $\mathrm{km} / \mathrm{h}$ and a $6.8 \mathrm{~m}$ storm surge. The storm continued inland, breaking windows and leading to flooding in many coastal areas and to power outages lasting several weeks in Houston.

Ike was the third costliest storm in U.S. history and the most costly storm in Texas history with more than $\$ 27.0$ billion (2008 U.S. dollars) in damages (Lott et al. [1]). This direct loss accounts for only a portion of the total economic loss attributable to Ike. Reduced spending due to production constraints and reduced consumer spending triggers wider losses as businesses buy fewer inputs from suppliers and/or lay off employees. In turn, supply businesses and former employees reduce expenditures as well. Different regions and industries may react differently based upon the structure of the regional economy and its internal linkages.

The economic reaction and recovery may also be affected by the type of disaster. Hurricanes have a massive effect on a relatively large region, and coastal areas tend to be heavily populated with a high concentration of economic activity. Hurricanes occur over a short period of time but require a long recovery period. These features make them ideal disasters for economic modeling. Wildfires may consume vast tracts of land but often occur in more rural settings with abundant fuel (e.g., dry grasses, brush, or trees). More populated places are generally better protected so population and economic activity are less dense in fire-devastated areas. Furthermore, the timing of a fire affects the extent to which farm commodities are destroyed, which can be a major factor in the economic consequences of the fire. Wildfires often build upon drought conditions, which can make fire-specific losses more difficult to identify.

Cross Plains, Texas, was engulfed by a wildfire December 27, 2005. The fire in Cross Plains, considered an urban wildland interface fire, was one fire within a 515-day Texas fire season caused by drought conditions and high winds (Gray 
[2]). The fire season in the state included the loss of 734 homes and 1,320 other structure. The Cross Plains fire accounted for 110 homes, 6 hotel units, and a church. These losses were significant in a city with 1,068 people and 554 housing units in 2000 (Census [3]). Most economic damage occurred outside urbanized areas in Callahan and Eastland counties as livestock, crops, and rangeland were destroyed. In Callahan County, 2,765 acres were destroyed, and 14,285 acres were destroyed in neighboring Eastland County.

The winter timing of the fire meant that fall crops had been harvested, spring crops were not yet planted, and fields of fall-planted spring crops (e.g., wheat) could be replanted with another crop. Rangeland used for livestock would begin to recover with spring rains, although it would initially be able to support fewer animals per acre. Both crops and livestock lost in the fire were eligible for agricultural insurance payments, which mitigated the loss for farmers and ranchers.

The paper proceeds as follows: Section 2 provides a brief review of the literature discussing the economic impacts of disasters, Section 3 describes the data, Section 4 introduces the methods, Section 5 discusses results, and Section 6 concludes.

\section{Review of the disaster impact literature}

Okuyama [4] provides a thorough but succinct discussion of the history of disaster impact analysis. Input-output analysis is a common method of impact analysis dating back to the 1940s. Input-output studies are popular because they reflect linkages between industries; even if an industry is not directly affected by the storm, it may be affected by changes in the spending patterns of other businesses and their consumers. Several studies use input-output and related methods to quantify the impact of storms on regional economies (Rose and Liao [5], Donaghy et al. [6], Okuyama et al. [7], and Xiao [8]).

West and Lenze [9], analyzing the impact of Hurricane Andres, note several challenges to calculating the regional impacts of disasters: the size of the event is not well known, the wide range of industries affected sets the stage for doublecounting, the event is neither exclusively supply- nor demand-driven, and the reactions of households are not well-understood. The expected effects of wealth change may not be applicable given loss of physical possessions, disrupted the links between income and spending, altered investment links, housing supply and demand shifts, and possible work-force and migration changes. Furthermore, sector demand may be atypical following a storm (e.g., an increase in construction), and jobs created may be temporary and attract migrant workers. Impact models do not generally account for these scenarios.

Swenson [10] notes that it is difficult to identify whether economic changes over time are attributable to a specific event, such as a natural disaster, rather than overall economic changes or a combination of events. Never-the-less, Mantell [11] points out that disasters require immediate attention and that models providing immediate results are needed. More complicated models may provide refined results at a later point. This study aims to provide a rapid-response model 
that is flexible enough to accommodate different types of disasters and economic structures and that can be refined as more data becomes available.

\section{Data}

The goal of the study was to model the recovery paths of industries within a disaster-impacted region with the county as the unit of analysis. In Texas, the Comptroller of Public Accounts (Combs [12]) publishes quarterly sales data for 20 industries defined at the two-digit NAICS level (Census Bureau [13]). The dataset includes all sales and taxable sales within each county and city going back to 2002, which is almost four years before the fire and six years before the hurricane. The comptroller's data site was used because it provides sub-annual data at the local level and because other states have comparable data, allowing the model to be expanded to other states.

Agricultural data is available only on an annual basis because most plant and animal commodities produce one crop per year. The variable of interest for the impact model is annual sales for each commodity. However, annual sales are estimated as a function of prices, production, acreage planted, and livestock counts. These data for 1998 through 2009 were obtained from the National Agricultural Statistics Service (U.S. Department of Agriculture [14]). Agricultural statistics dating back to 1968 are available at the county level for all states. Price and production data were obtained for corn, cotton, grain sorghum, rice, soybeans, wheat, beef cattle, goats, and sheep.

Data on national and state-level recessions were collected from the National Bureau of Economic Research [15]. However, no quarters in this study were considered recessionary. The 2001 recession ended before the sales tax data set began, and Texas remained insulated from the recession that began in December 2007 until 2009, after Hurricane Ike. Without past recessionary quarters in the dataset, no coefficient is estimated for future recessionary quarters.

It was important that data be general in nature so the model could be adapted to disasters in other regions and in future periods. Disasters often affect multiple states so similar data was required across states. The model predicted a stochastic growth path using data that could be readily available for future quarters. In the case of industry and services, the year and quarters occur regardless of whether an area is affected by a disaster. Recession data, if incorporated later, allow for normal or adverse-case recovery paths to be analysed. For agricultural commodities, previous year prices as well as planted acres and livestock counts are readily available and inform expectations about future sales.

\section{Methods}

The model uses three steps to determine the economic impact of a natural disaster on a regional economy. First, the sales path for each industry within each county is estimated using regression analysis with stochastic predictions for sales in future years. Second, weighted input-output multipliers are applied to industry sales estimates and observed sales data to capture economy-wide impacts. 
Finally, the total impacts for each industry are simulated stochastically to produce a range of loss estimates, and differences between stochastic predicted impacts and actual impacts are measured as the extent of the disaster.

\subsection{Stochastic modelling of expected sales paths}

Disasters cause a deviation in sales trends for most industries. Measuring the impact of a disaster requires predicting sales in a given industry had the disaster not occurred. For industries other than production agriculture, 2002-2011 sales (IndSales) for each industry $i$ and county $r$ were modeled as a function of time (Year) and calendar year quarter dummy variables (Qtr), eqn (1). The third quarter including July through September was omitted. The year and quarter variables accounted for trends over time and between quarters. The need to account for overarching economic events, such as the Great Recession, was recognized. However, no quarters were identified as recessionary during the study period so that variable was not used in the model estimation, although space for a Recession variable was retained in the Excel spreadsheet containing the model.

$$
\text { IndSales }_{\mathrm{i}, \mathrm{r}}=\alpha+\beta_{1} \text { Year }+\beta_{2} \mathrm{Qtr} 1+\beta_{3} \mathrm{Qtr} 2+\beta_{4} \mathrm{Qtr} 4+\beta_{5} \text { Recession }+\varepsilon
$$

Agricultural commodity sales (AgSales) were modeled based on the number of years from the 1999 base (BaseYr), the squared years from base (BaseYrSq), the previous year's commodity price (PrevYrP) and a dummy variable for disaster years (Disaster), eqn (2). The year variables accounted for production trends over time while previous year's price is associated with current year planting decisions and thus current year sales. Products that had only been grown a few times or that had not been grown in the last two years were not modeled. Data from 1999 to 2008 were used to estimate coefficients for each commodity.

$$
\text { AgSales }_{i, \mathrm{r},}=\alpha+\beta_{1} \text { BaseYr }+\beta_{2} \text { BaseYrSq }+\beta_{3} \text { PrevYrP }+\beta_{4} \text { Disaster }+\varepsilon
$$

Each industry-county combination was modeled using ordinary least squares (OLS) regression with Simetar ${ }^{\circledR}$ (Richardson et al. [16]). Based on the trend regressions, Simetar also generated stochastic forecasts for an additional eight quarters (later sixteen quarters) and two agricultural production years after Hurricane Ike (Q3 2008) to reflect production and price risk and the variability of production across years. The same methods were used to analyse the effects of the Cross Plains fire (Q4 2005) for eight quarters and two agricultural production years.

Simetar is a simulation language that allows researchers to simulate random variables, conduct parameter estimation and statistical analyses, manipulate and analyse data, and conduct regression and probabilistic forecasting. The Simetar functions are dynamic so most parameters, hypothesis tests, and regression models are automatically updated when new data is entered. Thus, in preparation for an impending disaster or in the immediate wake of a disaster, historical data 
from the affected region can be imported into the spreadsheet, and the OLS regressions and stochastic calculations will automatically update to reflect local economic relationships.

\subsection{Input-Output analysis of expected and actual sales}

The stochastic estimates for post-Ike quarters were combined with IMPLAN (Minnesota IMPLAN Group [17]) multipliers to estimate total economic losses following Hurricane Ike and the Cross Plains fire. IMPLAN is an input-output modelling tool originally developed by the USDA Forest Service and later privatized. IMPLAN provides the software tools and region-specific data to create and manipulate social accounting matrices for a user-defined region. These matrices are used to calculate multipliers to estimate impacts on 440 sectors of the regional economy. The change in final demand sales within a regional industry is the direct impact. The direct impact leads to indirect impacts as directly affected businesses purchase inputs from regional suppliers and induced impacts as employees of directly and indirectly affected businesses spend their incomes. The direct, indirect, and induced effects are collectively the total impact across the regional economy.

Comptroller data was available only at the two-digit sector level. However, IMPLAN uses more precise sector breakdowns in calculating industry multipliers. Therefore, the multipliers were weighted according to sales volume of each IMPLAN sector within a given two-digit NAICS sector. Agricultural commodities used the multipliers for their respective IMPLAN-assigned industry.

The weighted multipliers were applied to the stochastic sales predictions for each county's goods-producing and services industries to estimate actual and predicted total economic impacts quarterly. The initial analysis of Hurricane Ike included eight post-Ike quarters. The simulation was expanded to 16 quarters because many sectors had not recovered within two years, although only 11 quarters of sales data were available. Additional data can be added as it is posted to the Comptroller's website. Multipliers on agricultural commodities were used to estimate economy-wide impacts for two years post-disaster for crops and livestock. The fire in Callahan and Eastland counties was evaluated for two years (eight quarters).

\subsection{Simulation of sales impacts and calculation of economic losses by industry}

The total economic impact predictions for each industry/commodity and quarter/year were simulated using Simetar. The minimum, maximum, and mean total economic effect forecasts from the simulations were recorded as the average and bounds of the predicted industry sales. Stochastic effects were assigned a lower bound of zero as negative sales are precluded. The summary statistics were used to facilitate conversion to a web-based delivery format and to aid comprehension by community leaders and the general public. 
The weighted multipliers from IMPLAN were applied to the actual sales for each industry. The total impacts resulting from actual sales then were subtracted from minimum, maximum and mean predicted impacts for each industry to determine the average and bounds of economic losses within each county. Because the IMPLAN model is linear, subtracting actual impacts from predicted impacts is equivalent to applying the IMPLAN multipliers to the differences between actual from predicted direct sales. The method used here allows the full impact of the actual and predicted sales paths to be shown graphically. The economic losses for each industry were summed to calculate the economy-wide loss across all industries in a county.

\section{Results}

The model produces 20 industry-specific graphs for each county and up to nine graphs for agricultural commodities, depending upon the number of commodities produced in the county. An additional four graphs summarize the economic impacts on the goods-producing, service, and agricultural sectors and the entire economy for each county. Consequently, it is impractical to present all result data and graphs in this section. Furthermore, the aim of this paper is to present the methods used in developing the model; the case studies of Hurricane Ike and the Cross Plains fire serve to demonstrate and validate the model. Results presented in this section are intended to show the outputs of the model. Results from Galveston County are used to demonstrate the hurricane application of the model, and results from Eastland County demonstrate the adaptability of the model to a fire application. Full results from the first year following Hurricane Ike are available under the Learn tab at The Storm Resource website (http://thestormresource.com/learn.aspx, Texas Engineering Extension Service [18]).

\subsection{Hurricane Ike Results - Galveston County}

Hurricane Ike made landfall in coastal Galveston County with devastating results for homeowners and businesses. The county economy still had not recovered three years later (Fig. 1). The goods-producing sector, which comprised $96 \%$ of the county's economy in 2008 and $91 \%$ in 2010, was most damaged, both initially and throughout the prolonged recession. The recovery graph for the goods-producing sector is almost identical to that of the overall economy. The service sector was relatively more stable and rebounded after the completion of a massive new health services facility at the end of the study period. Agriculture is only a very small component of the county's economy.

Effects of the storm varied by industry. Some industries were extremely vulnerable and others more resilient. For example, transportation was effected only in the first quarter post-hurricane (Fig. 2, panel a). Manufacturing (panel b) declined in the first quarters after the hurricane and continued to perform poorly throughout the recession. The mining, oil, and gas sector was hurt by the 


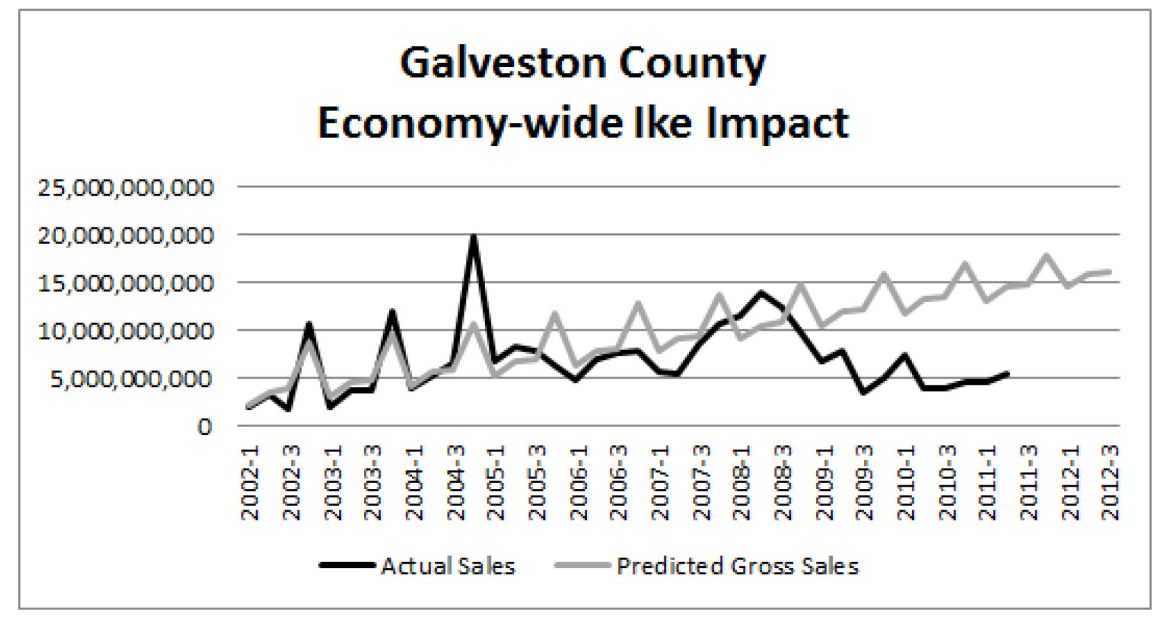

Figure 1: $\quad$ Predicted versus actual sales, full economy, Galveston County.

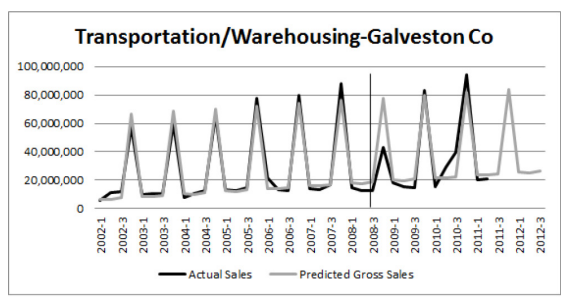

a

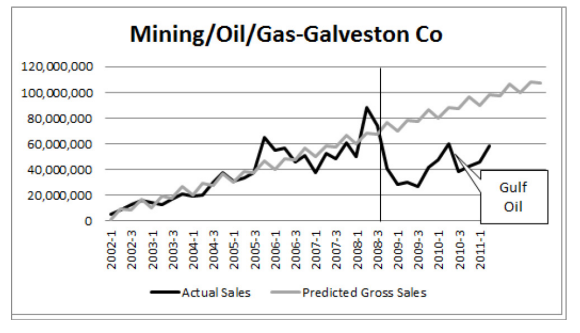

c

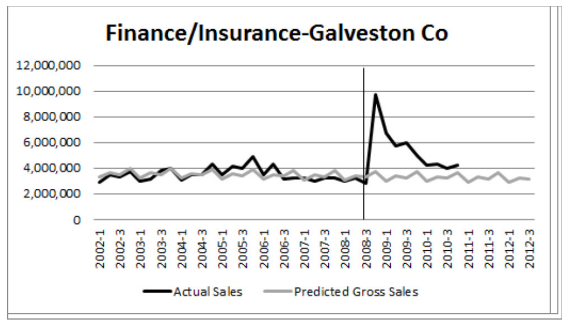

$\mathrm{e}$

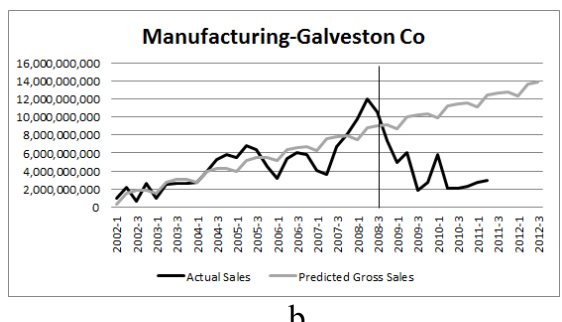

b
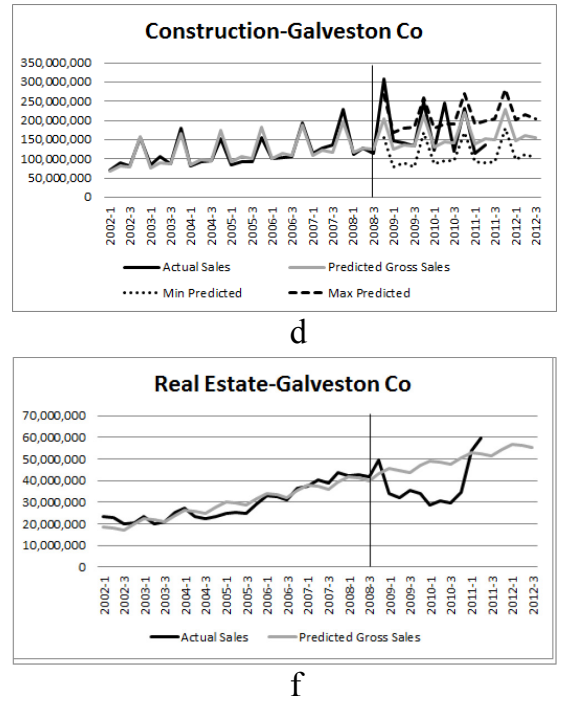

Figure 2: Predicted versus actual sales, selected industries, Galveston County. 
hurricane and received another setback in the form of the 2010 Deepwater Horizon oil spill (panel c). The construction sector outperformed expectations in the immediate aftermath of the hurricane and continued to perform well as residents and businesses rebuilt over time (panel d). Panel d also shows the minimum and maximum sales expectations for the construction sector. These lines were excluded from most published graphs because they were deemed confusing to the lay audience.

Within the service sector, the finance and insurance industry was notable for the immediate spike in activity following Hurricane Ike (Fig. 2, panel e). This activity slowly returned to predicted volumes. Real estate sales rose slightly immediately following the hurricane, perhaps as a result of small-firm reporting in the fourth quarter, but remained depressed until the first quarter of 2011 (panel f). Most service industry sales remained fairly similar to predicted values during the hurricane recovery period.

These results indicate that it is useful to examine individual industries as well as the overall economy. It is also important to note that a single industry may perform differently in counties with different economic structures and different levels of damage. For example, the hotel and restaurant industry experienced lower sales immediately in Galveston County but rose slightly in neighbouring Brazoria County, probably as a result of relief workers' accommodations.

\subsection{Wildfire results - Eastland County}

The impacts of the wildfires in Eastland and Callahan Counties were markedly different than those of Hurricane Ike. While many homes were destroyed by the December 2005 fire, much of the damage was to agricultural facilities and livestock. Both the construction and agriculture support industries experienced an increase in sales volume post-fire as residents replaced housing, agricultural structures, and fences (Fig. 3, panels a and b). Considering that most losses (both personal and agricultural) were insured, it is not surprising that retail trade remained fairly constant following the fire (panel c). Within the important agriculture sector in that county, only the beef cattle industry experienced significant losses (panel d). The fire occurred in winter after crops had been harvested, and farmers could plant fields with burned fall-planted crop (e.g., winter wheat) with a spring crop (e.g., corn). Cattle are the predominant livestock species in the region. Some cattle were destroyed by fire while others were sold due to a lack of forage for grazing following the fire and preceding drought. Thus, future herd sizes and sales declined.

\section{Conclusion}

The disaster impact model estimated economic losses to industries and counties within two study areas: eight counties directly affected by Hurricane Ike and two counties impacted by wildfire. Results provided by the DIM were larger than previous loss estimates that did not account for economic impacts, especially in the case of Hurricane Ike. Almost all sectors were negatively impacted by 


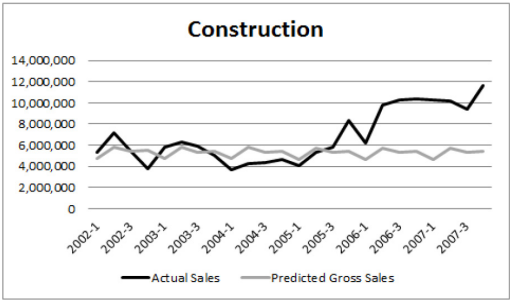

a

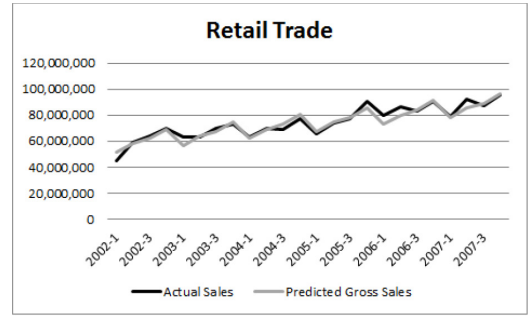

c

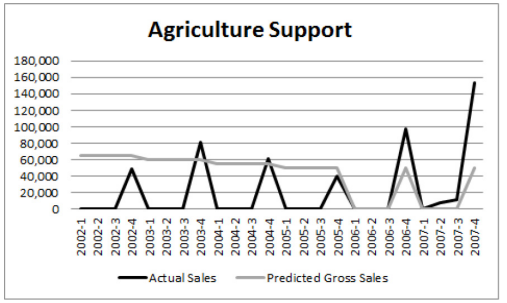

$\mathrm{b}$

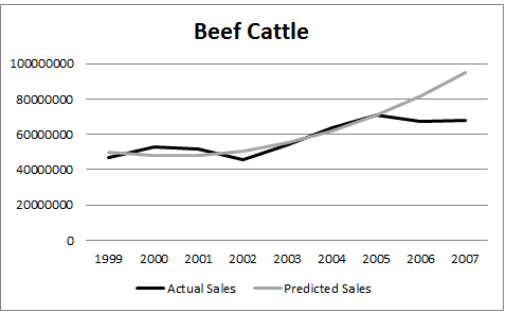

d

Figure 3: $\quad$ Predicted versus actual sales, selected industries, Eastland County.

Hurricane Ike, while only agricultural and construction industries were significantly affected by the central Texas wildfire, and even agricultural impacts from the winter fire were limited. The differing results between the two disasters helped to validate the model's sensitivity to the scope and type of disaster. The model also identified industries with a high degree of vulnerability as well as recovery paths for each industry. The model proved easy to update when new data was available and to adapt between disaster types (i.e., hurricane and wildfire).

A region's initial reaction and its resilience seem to be affected by the structure of the regional economy, which implies economic development strategies should include a disaster-preparedness component. Specifically, officials may be able to work with businesses in vulnerable industries to mitigate damage. This may include encouraging coordinated disaster planning across all sectors as well as working with key suppliers, such as utilities, to identify priority service restorations.

This information is useful to community leaders and planners with disasterpreparedness responsibilities. In fact, results from the first eight quarters following Hurricane Ike were interpreted in a web-based delivery system accessible by the general public. The model has the advantage that additional counties can be incorporated into the model quickly when disasters are impending. The model is also easy to update as new sales become available.

Local and state officials may be able to request and target disaster assistance based on modeled predictions. However, additional validation of the model is required to confidently predict losses ex-ante. Only eight counties experiencing a single hurricane prior to an international recession and only two counties experiencing a wildfire were modeled. Additional hurricanes and fires must be 
analyzed, preferably in other counties, to create a more robust data set and validate that losses and recovery paths are similar given the disaster type and timing and the regional economic structure. This is an area of ongoing research. Another avenue of further research is the incorporation of the DIM into a broader resilience analysis process that includes facility risk, service delivery and control systems, and system interdependences. Opportunities to broaden the resilience model as part of such a resilience tool are being explored.

\section{References}

[1] Lott, N., T. Ross., and M. Lackey. Billion Dollar U.S. Weather Disasters. Silver Spring, MD: National Oceanic and Atmospheric Administration, Satellite and Information Service, January. Available at http://www.ncdc.noaa.gov/oa/reports/billionz.html. 2011.

[2] Gray, R., M. Dunivan, J. Jones, K. Ridenour, M. Leathers, and K. Stafford. Cross Plains, Texas Wildland Fire Case Study. Texas Forest Service Urban Wildland Interface Division, May. 2007.

[3] Census Bureau, U.S. Department of Commerce. American Factfinder, 2000 Census. Available at http://factfinder2.census.gov/faces/nav/jsf/pages /index.xhtml. 2013.

[4] Okuyama, Y. "Economic Modeling for Disaster Impact Analysis: Past, Present, and Future." Economic Systems Research 19(2): 115-124. 2007.

[5] Rose, A., and S.-Y. Liao. "Modeling Regional Economic Resilience to Disasters: A Computable General Equilibrium Analysis of Water Service Disruptions." Journal of Regional Science 45(1):75-112. 2005.

[6] Donaghy, K.P., Balta-Ozkan, N.; Hewings, G.J.D. "Modeling Unexpected Events in Temporally Disaggregated Econometric Input-Output Models of Regional Economies.” Economic Systems Research 19(2): 125-145. 2007.

[7] Okuyama, Y., G.J.D. Hewings, and M. Sonis. "Measuring Economic Impacts of Disasters: Interregional Input-Output Analysis Using Sequential Interindustry Model." In Y. Okuyama and S.E. Chang (Eds) Modeling Spatial and Economic Impacts of Disasters, pp. 77-101. New York: Springer. 2004.

[8] Xiao, Y. "Local Economic Impacts of Natural Disasters", Journal of Regional Science, 51(4): 804-820. 2011.

[9] West, C.T., and D.G. Lenze. "Modeling the Regional Impact of Natural Disaster and Recovery: A General Framework and an Application to Hurricane Andrew. International Regional Science Review 17(2): 121-150. 1994.

[10] Swenson, D. Statewide Economic Impacts of Disaster-related Payments to Support Household and Private and Public Sector Recovery in Iowa. Rebuild Iowa Office: Des Moines, IA. January. 2010.

[11] Mantell, N.H. 2005. Book Review of "Modeling Spatial and Economic Impacts of Disasters," Journal of Regional Science: 45: 633-635. 
[12] Combs, S. Quarterly Sales Tax Historical Data. Texas Comptroller of Public Accounts. Online. Available at https://ourcpa.cpa.state.tx.us /allocation/HistSales.jsp. 2012.

[13] Census Bureau, U.S. Department of Commerce. North American Industry Classification System. Available at http://www.census.gov/cgi-bin/sssd /naics/naicsrch?chart $=2012.2012$.

[14] U.S. Department of Agriculture, National Agricultural Statistics Service. Texas Statistics. Available at http://www.nass.usda.gov/Statistics_by State/Texas/index.asp. 2009.

[15] National Bureau of Economic Research. Business Cycle Expansions and Contractions. Available at http://www.nber.org/cycles.html. 2008.

[16] Richardson, J.W., K.D. Schumann, and P.A. Feldman. Simetar ${ }^{\circledR}$. 2008.

[17] Minnesota IMPLAN Group, Inc. IMPLAN System [data and software], 502 2nd Street, Suite 301, Hudson, WI 54016. Available at www.implan.com. 2010.

[18] Texas Engineering Extension Service, Knowledge Engineering. The Storm Resource. Available at http://thestormresource.com. 2011. 